Sains Malaysiana 50(1)(2021): 261-278

http://dx.doi.org/10.17576/jsm-2021-5001-25

\title{
A Bayesian Approach for Estimation of Coefficients of Variation of Normal Distributions
}

\author{
(Pendekatan Bayesian untuk Anggaran Pekali Variasi Taburan Normal) \\ WARISA ThangJaI, SA-AAT NiWITPONG* \& SUPARAT NiWITPONG
}

\begin{abstract}
The coefficient of variation is widely used as a measure of data precision. Confidence intervals for a single coefficient of variation when the data follow a normal distribution that is symmetrical and the difference between the coefficients of variation of two normal populations are considered in this paper. First, the confidence intervals for the coefficient of variation of a normal distribution are obtained with adjusted generalized confidence interval (adjusted GCI), computational, Bayesian, and two adjusted Bayesian approaches. These approaches are compared with existing ones comprising two approximately unbiased estimators, the method of variance estimates recovery (MOVER) and generalized confidence interval (GCI). Second, the confidence intervals for the difference between the coefficients of variation of two normal distributions are proposed using the same approaches, the performances of which are then compared with the existing approaches. The highest posterior density interval was used to estimate the Bayesian confidence interval. Monte Carlo simulation was used to assess the performance of the confidence intervals. The results of the simulation studies demonstrate that the Bayesian and two adjusted Bayesian approaches were more accurate and better than the others in terms of coverage probabilities and average lengths in both scenarios. Finally, the performances of all of the approaches for both scenarios are illustrated via an empirical study with two real-data examples.
\end{abstract}

Keywords: Bayesian approach; coefficient of variation; difference; normal distribution; simulation

\section{ABSTRAK}

Pekali variasi digunakan secara meluas sebagai ukuran ketepatan data. Selang kepercayaan untuk pekali variasi tunggal apabila data mengikuti taburan normal yang simetris dan perbezaan antara pekali variasi dua populasi normal dipertimbangkan dalam makalah ini. Pertama, selang kepercayaan untukpekali variasi sebaran normal diperoleh dengan selang kepercayaan umum yang disesuaikan (GCI disesuaikan), pengiraan, Bayesian dan dua pendekatan Bayesian yang disesuaikan. Pendekatan ini dibandingkan dengan pendekatan sedia ada yang terdiri daripada dua penganggar yang tidak berat sebelah, kaedah pemulihan anggaran varians (MOVER) dan selang kepercayaan umum (GCI). Seterusnya, selang kepercayaan untuk perbezaan antara koefisien variasi dua taburan normal diusulkan menggunakan pendekatan yang sama, persembahannya kemudian dibandingkan dengan pendekatan yang ada. Selang ketumpatan posterior tertinggi digunakan untuk menganggar selang keyakinan Bayesian. Simulasi Monte Carlo digunakan untuk menilai prestasi selang kepercayaan. Hasil kajian simulasi menunjukkan bahawa pendekatan Bayesian dan dua Bayesian yang disesuaikan lebih tepat dan lebih baik daripada yang lain daripada segi kebarangkalian liputan dan panjang purata dalam kedua-dua senario tersebut. Akhirnya, prestasi semua pendekatan untuk kedua-dua senario digambarkan melalui kajian empirik dengan dua contoh data sebenar.

Kata kunci: Pendekatan Bayesian; pekali variasi; perbezaan; simulasi; taburan normal

\section{INTRODUCTION}

The coefficient of variation is defined as the ratio of the standard deviation to the mean (and thus is unit free) and is used as a measure of the precision and repeatability of a data series. The coefficient of variation has been applied in many fields, such as business, climatology, science, medicine, economics, life insurance, environment, among others. For instance, the coefficient of variation has been used as a measure of precision within and between laboratories in science (Tian 2005), for the measurement of blood samples taken from different laboratories (Chow et al. 1998), to evaluate the variability in strength of building 
materials in engineering and the physical properties of composite materials (Lim et al. 2018), and to measure the prevalence of smoking in tobacco controlled environments (Bernat et al. 2009). Moreover, using the coefficient of variation has been mentioned in other studies (McKay 1932; Singh 1993). Moreover, control charts are often used to monitor the coefficient of variation in quality control applications (Kang et al. 2007; Menzefricke 2010; van Zyl \& van der Merwe 2017; Zhang et al. 2018).

Several researchers have considered the statistical inference of using the coefficient of variation of a normal distribution. For instance, Doornbos and Dijkstra (1983) conducted a multi sample test for the equality of coefficients of variation in normal populations. Weerahandi (1995) introduced exact statistical methods for the coefficient of variation of a normal distribution. Vangel (1996) presented confidence intervals for the coefficient of variation of a normal distribution. Fung and Tsang (1998) reviewed several parametric and non-parametric tests for the equality of coefficients of variation for $\mathrm{k}$ populations. Wong and $\mathrm{Wu}$ (2002) presented small sample asymptotic inference for the coefficient of variation for normal and non-normal models. Tian (2005) developed an approach using the concepts of generalized variables for confidence interval estimation and hypothesis testing for the common coefficient of variation based on several independent normal samples. Verrill and Johnson (2007) studied the confidence bounds and hypothesis testing for normal distribution coefficients of variation. Taye and Njuho (2008) examined and compared different approaches for constructing the confidence interval for the coefficient of variation of a normal distribution. Mahmoudvand and Hassani (2009) provided two approximately unbiased estimators for the confidence intervals for the coefficient of variation of a normal distribution. Liu et al. (2015) proposed new approaches for the coefficient of variation of normal distribution. Gulhar et al. (2012) compared some confidence intervals for estimating the population coefficient of variation of normal, Chi-squared and gamma distributions. Donner and Zou (2012) developed the method of variance estimates recovery (MOVER) approach to construct the confidence interval for the coefficient of variation of a normal distribution. Saelee et al. (2013) developed a new approximation method for determining the confidence intervals for the coefficients of variation of normal distributions. Niwitpong (2015) reviewed the confidence intervals for the difference between coefficients of variation of normal distributions and proposed new ones for this scenario with bounded parameters. Recently, Thangjai et al. (2020) presented adjusted generalized confidence intervals (adjusted GCIs) for the common coefficient of variation of several normal populations.
In statistical inference, there are two ways to interpret of probability: Frequentist or classical inference and Bayesian inference. Frequentist inference defines probability as the limit of an event's relative frequency for a large number of experiments whereas Bayesian inference defines probability as the way to represent an individual's degree of belief in a statement. In Bayesian inference, the probability distributions represent prior uncertainty in the model parameters which are subsequently updated with respect to the given data. Hence, this gives rise to the posterior distribution as a combination of information from the prior distribution and the data. Camara (2003) proposed approximate Bayesian confidence intervals for the variance of a Gaussian distribution. Harvey et al. (2010) compared the Bayesian confidence intervals for the mean of a log-normal distribution with MOVER and generalized confidence interval (GCI). Camara (2012) presented new approximate Bayesian confidence intervals for the coefficient of variation of a Gaussian distribution. Harvey and van der Merwe (2012) provided Bayesian confidence intervals for the means and variances of lognormal and bivariate log-normal distributions. Rao and D'Cunha (2016) proposed Bayesian inference for the median of a log-normal distribution.

In this study, we develop novel approaches to estimate the confidence intervals for the single coefficient of variation of a normal distribution and confidence intervals for the difference between the coefficients of variation of two normal distributions are constructed using new approaches. Mahmoudvand and Hassani (2009) proposed two approximately unbiased estimators using the concept of pivotal statistics to construct the confidence intervals for the coefficient of variation of a normal distribution. Moreover, Donner and Zou (2012) presented a confidence interval for the coefficient of variation of a normal distribution based on the MOVER. Herein, we propose GCI, adjusted GCI, computational, Bayesian, and two adjusted Bayesian approaches for the confidence interval estimation of the coefficient of variation of a normal distribution. Recently, Niwitpong (2015) presented three approaches based on the concepts of Mahmoudvand and Hassani (2009) and Donner and Zou (2012) for the confidence interval estimation of the difference between the coefficients of variation of two normal distributions with bounded parameters. Herein, we provide the GCI, adjusted GCI, computational, Bayesian, and two adjusted Bayesian approaches to construct the confidence intervals for the difference between the coefficients of variation of two normal distributions. All of these approaches for the two scenarios are summarized in Table 1. 
TABLE 1. Approaches for the confidence intervals for a single coefficient of variation and the difference between the coefficients of variation

\begin{tabular}{cccc}
\hline \multicolumn{2}{c}{$\begin{array}{c}\text { Confidence intervals for single } \\
\text { coefficient of variation }\end{array}$} & $\begin{array}{c}\text { Confidence intervals for difference between coefficients } \\
\text { of variation }\end{array}$ \\
\hline Existing approach & Proposed approach & Existing approach & Proposed approach \\
\hline $\begin{array}{c}\text { Mahmoudvand and } \\
\text { Hassani } \\
\text { (MH1 and MH2) }\end{array}$ & $\begin{array}{c}\text { Adjusted Generalized } \\
\text { Confidence Interval } \\
\text { (AGCI) }\end{array}$ & $\begin{array}{c}\text { Mahmoudvand and } \\
\text { Hassani } \\
\text { (MH1 and MH2) }\end{array}$ & $\begin{array}{c}\text { Adjusted Generalized } \\
\text { Confidence Interval } \\
\text { (AGCI) }\end{array}$ \\
$\begin{array}{c}\text { Method of Variance } \\
\begin{array}{c}\text { Estimates Recovery } \\
\text { (MOVER) }\end{array}\end{array}$ & $\begin{array}{c}\text { Computational Approach } \\
\text { (CA) }\end{array}$ & $\begin{array}{c}\text { Method of Variance } \\
\text { Estimates Recovery } \\
\text { (MOVER) }\end{array}$ & $\begin{array}{c}\text { Computational Approach } \\
\text { (CA) }\end{array}$ \\
\hline $\begin{array}{c}\text { Generalized Confidence } \\
\text { Interval (GCI) }\end{array}$ & $\begin{array}{c}\text { Bayesian } \\
\text { (BS) }\end{array}$ & $\begin{array}{c}\text { Generalized Confidence } \\
\text { Interval (GCI) }\end{array}$ & $\begin{array}{c}\text { Bayesian } \\
\text { (BS) }\end{array}$ \\
\hline
\end{tabular}

The rest of the paper is organized as follows. Methods for estimating the confidence intervals for the coefficient of variation of a normal distribution is provided in the next section. Subsequent section presents the confidence intervals for the difference between the coefficients of variation of two normal distributions. After that, simulation studies are carried out to evaluate the coverage probabilities and average lengths of the confidence intervals for the coefficient of variation and the difference between the coefficients of variation of two normal distributions. This is followed by the computation of the all approaches, illustrated using two examples. And finally, last section summarizes this paper.

\section{CONFIDENCE INTERVALS FOR SINGLE COEFFICIENT OF VARIATION OF A NORMAL DISTRIBUTION}

Let $X=\left(X_{1}, X_{2}, \ldots, X_{n}\right)$ be a random sample from the normal distribution with mean $\mu$ and variance $\sigma^{2}$. The coefficient of variation is defined as the ratio of the standard deviation to the mean, denoted as $\theta=\sigma / \mu$ with $\mu \neq 0$.

Let $\bar{X}$ and $S^{2}$ be sample mean and sample variance, respectively. It is known that the unbiased estimators of $\mu$ and $\sigma^{2}$ are $\bar{X}$ and $S^{2}$, respectively. Also, let $\bar{x}$ and $s^{2}$ be observed values of $\bar{X}$ and $S^{2}$, respectively. The estimator of $\theta$ is $\hat{\theta}=S / \bar{X}$. Since this estimator is biased estimator.

According to Mahmoudvand and Hassani (2009) and Thangjai et al. (2020), the asymptomatically unbiased estimator of $\theta$ is defined as

$$
\widetilde{\theta}=\frac{\hat{\theta}}{2-c_{n}},
$$

where $c_{n}=\sqrt{2 /(n-1)}(\Gamma(n / 2) / \Gamma((n-1) / 2))$.

\section{EXISTING APPROACH FOR CONFIDENCE INTERVAL FOR SINGLE COEFFICIENT OF VARIATION}

Mahmoudvand and Hassani Approach for Confidence Interval for Single Coefficient of Variation

Mahmoudvand and Hassani (2009) proposed the two confidence intervals for the single coefficient of variation of normal distribution. The $100(1-\alpha) \%$ two-sided confidence intervals for the single coefficient of variation are defined by

$$
C I_{\theta . M H 1}=\left[\frac{\hat{\theta}}{2-c_{n}+z_{1-\alpha / 2} \sqrt{1-c_{n}^{2}}}, \frac{\hat{\theta}}{2-c_{n}-z_{1-\alpha / 2} \sqrt{1-c_{n}^{2}}}\right]
$$

and

$C I_{\theta . M H 2}=\left[\tilde{\theta}-\frac{\tilde{\theta}}{2-c_{n}} z_{1-\alpha / 2} \sqrt{\left(1-c_{n}^{2}\right)+\frac{\widetilde{\theta}^{2}}{n}}, \widetilde{\theta}+\frac{\tilde{\theta}}{2-c_{n}} z_{1-\alpha / 2} \sqrt{\left(1-c_{n}^{2}\right)+\frac{\widetilde{\theta}^{2}}{n}}\right],(3)$

where $\hat{\theta}=S / \bar{X}, \widetilde{\theta}=\hat{\theta} /\left(2-c_{n}\right)$, and $c_{n}=\sqrt{2 /(n-1)}(\Gamma(n / 2) /$ $\Gamma((n-1) / 2))$.

MOVER Approach for Confidence Interval for Single Coefficient of Variation

Donner and Zou (2012) introduced the MOVER approach to construct the confidence interval for the single coefficient of variation of normal distribution. The $100(1-\alpha) \%$ two-sided confidence interval for the single coefficient of variation based on the MOVER approach is defined by 
$C I_{\theta \text { MOVER }}=\left[\frac{S}{d}\left(\bar{X}-\sqrt{\max \left(0, \bar{X}^{2}+a d(a-2)\right)}\right), \frac{S}{d}\left(\bar{X}+\sqrt{\max \left(0, \bar{X}^{2}+b d(b-2)\right)}\right)\right]$,

where $a=\sqrt{(n-1) / u_{1}}, b=\sqrt{(n-1) / u_{2}}, d=\bar{X}^{2}-z_{\alpha / 2} S^{2} / n$, $u_{1} \sim \chi_{1-\alpha / 2, n-1}^{2}$, and $u_{2} \sim \chi_{\alpha / 2, n-1}^{2}$.

GCI Approach for Confidence Interval for Single Coefficient of Variation

Liu et al. (2015) proposed the GCI approach for constructing the confidence interval for normal coefficient of variation. Let $R_{\theta}(\alpha / 2)$ and $R_{\theta}(1-\alpha / 2)$ are the $100(\alpha / 2)$-th and the $100(1-\alpha / 2)$-th percentiles of $R_{\theta}$, respectively. The $100(1-\alpha) \%$ two-sided confidence interval for the single coefficient of variation based on the GCI approach is obtained by

$C I_{\theta . G C I}=\left[L_{\theta . G C I}, U_{\theta . G C I}\right]=\left[R_{\theta}(\alpha / 2), R_{\theta}(1-\alpha / 2)\right]$,

where $R_{\theta}=\sqrt{R_{\sigma^{2}}} / R_{\mu}, R_{\sigma^{2}}=(n-1) s^{2} / \chi_{n-1}^{2}, R_{\mu}=\bar{x}-Z \sqrt{R_{\sigma^{2}} / n}$, $\chi_{n-1}^{2}$ is the chi-squared distribution with $n-1$ degrees of freedom, and $Z$ is the standard normal distribution.

\section{PROPOSED APPROACH FOR CONFIDENCE INTERVAL FOR} SINGLE COEFFICIENT OF VARIATION

Adjusted GCI Approach for Confidence Interval for Single Coefficient of Variation

The GCI approach uses the generalized pivotal quantity for $\hat{\theta}$ to construct the confidence interval for the single coefficient of variation. Then, the confidence interval constructed by the generalized pivotal quantity for $\tilde{\theta}$ is called that the adjusted GCI approach. The generalized pivotal quantity for $\tilde{\theta}$ is defined as

$$
R_{\widetilde{\theta}}=\frac{R_{\theta}}{2-c_{n}}=\frac{1}{\left(2-c_{n}\right)}\left(\frac{\sqrt{(n-1) s^{2} / \chi_{n-1}^{2}}}{\bar{x}-Z \sqrt{(n-1) s^{2} / n \chi_{n-1}^{2}}}\right) .
$$

Therefore, the 100(1- $\alpha) \%$ two-sided confidence interval for the single coefficient of variation based on the adjusted GCI approach is obtained by

$$
C I_{\theta . A G C I}=\left[L_{\theta . A G C I}, U_{\theta . A G C I}\right]=\left[R_{\widetilde{\theta}}(\alpha / 2), R_{\widetilde{\theta}}(1-\alpha / 2)\right],
$$

where $R_{\widetilde{\theta}}(\alpha / 2)$ and $R_{\widetilde{\theta}}(1-\alpha / 2)$ are the $100(\alpha / 2)$-th and the $100(1-\alpha / 2)$-th percentiles of $R_{\widetilde{\theta}}$, respectively. The following algorithm is used to construct the adjusted GCI for the single coefficient of variation of normal distribution:

Algorithm 1

Step 1: Generate $\chi_{n-1}^{2}$ from chi-squared distribution with $n-1$ degrees of freedom and $Z$ from standard normal distribution; Step 2: Compute $R_{\widetilde{\theta}}$ from (6); Step 3: Repeat step 1 - step 2, a total $q$ times and obtain an array of $R_{\widetilde{\theta}}$ 's; and Step 4: Compute $R_{\widetilde{\theta}}(\alpha / 2)$ and $R_{\widetilde{\theta}}(1-\alpha / 2)$.

Computational Approach for Confidence Interval for Single Coefficient of Variation

Computational approach applies the concept of computational approach test (CAT). Application of the CAT can be found in Gül et al. (2019). The CAT uses for the equality of coefficient of variation in $k$ populations. The CAT is used on simulation and numerical computation which uses the maximum likelihood estimates (MLEs). The computational approach recalculates the maximum likelihood estimate of new data.

Let $\hat{\mu}_{R M L}$ and $\hat{\sigma}_{R M L}^{2}$ be restricted maximum likelihood (RML) estimator of parameters $\mu$ and $\hat{\sigma}^{2}$, respectively. Let artificial sample $X_{R M L}=\left(X_{1 . R M L}, X_{2 . R M L}, \ldots, X_{n . R M L}\right)$ be the normal distribution with mean $\hat{\mu}_{R M L}=\bar{X}$ and variance $\hat{\sigma}_{R M L}^{2}=(n-1) S^{2} / n$. Let $\bar{X}_{R M L}$ and $S_{R M L}^{2}$ be sample mean and sample variance of $X_{R M L}$, respectively. Also, let $\bar{x}_{R M L}$ and $s_{R M L}^{2}$ be observed values of $\bar{X}_{R M L}$ and $S_{R M L}^{2}$ , respectively.

Hence, the estimator of coefficient of variation is defined as

$$
\hat{\theta}_{R M L}=\frac{S_{R M L}}{\bar{X}_{R M L}} .
$$

Therefore, the $100(1-\alpha) \%$ two-sided confidence interval for the single coefficient of variation based on the computational approach is obtained by

$$
C I_{\theta . C A}=\left[L_{\theta . C A}, U_{\theta . C A}\right]=\left[\hat{\theta}_{R M L}(\alpha / 2), \hat{\theta}_{R M L}(1-\alpha / 2)\right],
$$

where $\hat{\theta}_{R M L}(\alpha / 2)$ and $\hat{\theta}_{R M L}(1-\alpha / 2)$ are the $100(\alpha / 2)$-th and the $100(1-\alpha / 2)$-th percentiles of $\hat{\theta}_{R M L}$, respectively.

The following algorithm is used to construct the computational confidence interval for the single coefficient of variation of normal distribution:

Algorithm 2

Step 1: Generate $x_{R M L}$ from $N\left(\hat{\mu}_{R M L}, \hat{\sigma}_{R M L}^{2}\right)$; Step 2: Compute $\bar{x}_{R M L}$ and $s_{R M L}^{2}$; Step 3: Compute $\hat{\theta}_{R M L}$ from (7); Step 4: Repeat step 1 - step 3, a total $q$ times and obtain an array of $\hat{\theta}_{R M L}$ 's; and Step 5: Compute $\hat{\theta}_{R M L}(\alpha / 2)$ and $\hat{\theta}_{R M L}(1-\alpha / 2)$.

Bayesian Approach for Confidence Interval for Single Coefficient of Variation

Bayesian approach uses Bayes' theorem which is used to update the probability for hypothesis as more evidence becomes available, see Bayes (1763). This approach derives the posterior probability. The posterior 
probability is based on the likelihood function and the prior probability. The likelihood function is a function of the evidence. The prior probability is the estimate of the probability of the hypothesis before the data is observed. Let $x=\left(x_{1}, x_{2}, \ldots, x_{n}\right)$ be observed value of $X=\left(X_{1}, X_{2}, \ldots, X_{n}\right)$. The posterior distribution is computed according the Bayes' rule as follows: $P(\gamma \mid x)=P(\gamma) P(x \mid \gamma) / P(x)$, where $\gamma=\left(\mu, \sigma^{2}\right)$ is the set of parameter, $P(\gamma \mid x)$ is the posterior probability, $P(\gamma)$ is the prior probability, $P(x \mid \gamma)$ is likelihood function, and $P(x)$ is the marginal likelihood.

The posterior distribution is proportional to the product of the likelihood and prior is the accurate description of Bayes' theorem. The independence Jeffreys prior distribution follows from the Fisher information matrix (Tongmol et al. 2016). The independence Jeffreys prior is obtain by $P\left(\mu, \sigma^{2}\right) \propto 1 / \sigma^{2}$. Therefore, the conditional posterior distribution for $\mu$ given $\sigma^{2}$ and $x$ defined by $\mu \mid \sigma^{2}, x$ is the normal distribution. The distribution of $\mu \mid \sigma^{2}, x$ is defines as

$$
\mu \mid \sigma^{2}, x \sim N\left(\hat{\mu}, \frac{\sigma^{2}}{n}\right) .
$$

Furthermore, the posterior distribution for $\sigma^{2}$ defined by $\sigma^{2} \mid x$ is inverse gamma distribution which is defined as

$$
\sigma^{2} \mid x \sim I G\left(\frac{v}{2}, \frac{v s^{2}}{2}\right),
$$

where $v=n-1$.

Bayesian approach uses posterior distribution of coefficient of variation to construct the confidence interval through Monte Carlo simulation. Since the posterior distribution of coefficient of variation of normal distribution is defined as

$$
\theta_{B S}=\frac{\sigma}{\mu}
$$

where $\mu$ and $\sigma=\sqrt{\sigma^{2}}$ are simulated from the posterior distributions as defined in (10) and (11), respectively. The Bayesian computation for the posterior of $\theta_{B S}=\sigma / \mu$ is used the standard routines in the simulation procedure, see Algorithm 3.

The posterior distribution is used to construct the Bayesian confidence interval. Gelman et al. (2013) proposed that a slightly different summary of posterior uncertainty is the highest posterior density interval. The set of values contains $100(1-\alpha) \%$ of the posterior probability. Furthermore, the density within the region is never lower than the density outside the region. If the posterior distribution is unimodal and symmetric, then this region is identical to a central posterior interval. Therefore, the $100(1-\alpha) \%$ two-sided confidence interval for the single coefficient of variation based on the Bayesian approach is obtained by

$$
C I_{\theta . B S}=\left[L_{\theta . B S}, U_{\theta . B S}\right],
$$

where $L_{\theta . B S}$ and $U_{\theta . B S}$ are the lower limit and the upper limit of the shortest $100(1-\alpha) \%$ highest posterior density interval of $\theta_{B S}$, respectively.

The following algorithm is used to construct the Bayesian confidence interval for the single coefficient of variation of normal distribution:

\section{Algorithm 3}

Step 1: Generate $\sigma^{2} \mid x \sim I G\left(v / 2, v s^{2} / 2\right)$; Step 2: Generate $\mu \mid \sigma^{2}, x \sim N\left(\hat{\mu}, \sigma^{2} / n\right)$; Step 3: Compute $\theta_{B S}$ from Equation (12); Step 4: Repeat step 1 - step 3, a total $q$ times and obtain an array of $\theta_{B S}$ 's; and Step 5: Compute $L_{\theta . B S}$ and $U_{\theta . B S}$.

Adjusted Bayesian Approach for Confidence Interval for Single Coefficient of Variation

Bayesian approach uses posterior of $\theta_{B S}=\sigma / \mu$. The adjusted Bayesian approach is motivated based on the Bayesian approach which uses posteriors of $R_{\theta}$ of Liu et al. (2015) and $R_{\widetilde{\theta}}$ defined in (6). In this study, two adjusted Bayesian confidence intervals are constructed based on the adjusted Bayesian approach using the GCI approach based on the generalized pivotal quantity of Liu et al. (2015) and the adjusted GCI approach based on the generalized pivotal quantity in (6).

First, the generalized pivotal quantity $R_{\theta}$ of Liu et al. (2015) is used to construct the confidence interval based on the adjusted Bayesian approach. Therefore, the $100(1-\alpha) \%$ two-sided confidence interval for the single coefficient of variation based on the adjusted Bayesian approach using the GCI approach based on the generalized pivotal quantity of Liu et al. (2015) is obtained by

$$
C I_{\theta . A B S 1}=\left[L_{\theta . A B S 1}, U_{\theta . A B S 1}\right],
$$

where $L_{\theta . A B S 1}$ and $U_{\theta . A B S 1}$ are the lower limit and the upper limit of the shortest $100(1-\alpha) \%$ highest posterior density interval of $R_{\theta}$, respectively.

Second, the adjusted Bayesian confidence interval is constructed based on the generalized pivotal quantity $R_{\widetilde{\theta}}$ in (6). Therefore, the $100(1-\alpha) \%$ two-sided confidence interval for the single coefficient of variation based on the adjusted Bayesian approach using the adjusted GCI approach based on the generalized pivotal quantity in equation (6) is obtained by

$$
C I_{\theta . A B S 2}=\left[L_{\theta . A B S 2}, U_{\theta . A B S 2}\right],
$$

where $L_{\theta . A B S 2}$ and $U_{\theta . A B S 2}$ are the lower limit and the upper limit of the shortest $100(1-\alpha) \%$ highest posterior density interval of $R_{\widetilde{\theta}}$, respectively. 
The following algorithm is used to construct the adjusted Bayesian confidence interval for the single coefficient of variation of normal distribution:

\section{Algorithm 4}

Step 1: Generate $\chi_{n-1}^{2}$ from chi-squared distribution with $n-1$ degrees of freedom and $Z$ from standard normal distribution; Step 2: Compute $R_{\theta}$ and $R_{\widetilde{\theta}}$; Step 3: Repeat step 1 - step 2, a total $q$ times and obtain array of $R_{\theta}$ 's and array of $R_{\widetilde{\theta}}$ 's; Step 4: Compute $L_{\theta . A B S S}$; Step 5: Compute $U_{\theta . A B S 1}$; Step 6: Compute $L_{\theta . A B S 2}$; and Step 7: Compute $U_{\theta . A B S 2}$.

CONFIDENCE INTERVALS FOR THE DIFFERENCE BETWEEN THE COEFFICIENTS OF VARIATION OF TWO NORMAL DISTRIBUTIONS

Let $X=\left(X_{1}, X_{2}, \ldots, X_{n}\right)$ and $Y=\left(Y_{1}, Y_{2}, \ldots, Y_{m}\right)$ be random samples from two normal distributions with means $\mu_{X}, \mu_{Y}$ and variances $\sigma_{X}^{2}, \sigma_{Y}^{2}$. The coefficients of variation of $X$ and $Y$ are $\theta_{X}=\sigma_{X} / \mu_{X}$ and $\theta_{Y}=\sigma_{Y} / \mu_{Y}$, respectively. The difference of coefficients of variation is defined by

$$
\delta=\theta_{X}-\theta_{Y}=\frac{\sigma_{X}}{\mu_{X}}-\frac{\sigma_{Y}}{\mu_{Y}} .
$$

Let $\bar{X}$ and $S_{X}^{2}$ be sample mean and sample variance of $X$, respectively, let $\bar{Y}$ and $S_{Y}^{2}$ be sample mean and sample variance of $Y$, respectively. Also, let $\bar{x}, \bar{y}, s_{X}^{2}$ , and $s_{Y}^{2}$ be observed values of $\bar{X}, \bar{Y}, S_{X}^{2}$, and $S_{Y}^{2}$, respectively. The maximum likelihood estimator of $\delta$ is obtained by

$$
\hat{\delta}=\hat{\theta}_{X}-\hat{\theta}_{Y}=\frac{S_{X}}{\bar{X}}-\frac{S_{Y}}{\bar{Y}} .
$$

Moreover, the asymptomatically unbiased estimator of $\delta$ is obtained by:

$$
\widetilde{\delta}=\widetilde{\theta}_{X}-\widetilde{\theta}_{Y}=\frac{\hat{\theta}_{X}}{2-c_{n}}-\frac{\hat{\theta}_{Y}}{2-c_{m}},
$$

where $c_{n}=\sqrt{2 /(n-1)}(\Gamma(n / 2) / \Gamma((n-1) / 2))$ and $c_{m}=\sqrt{2 /(m-1)}$ $(\Gamma(m / 2) / \Gamma((m-1) / 2)) \cdot$

\section{EXISTING APPROACH FOR THE DIFFERENCE BETWEEN THE COEFFICIENTS OF VARIATION}

Mahmoudvand and Hassani Approach for Confidence Interval for the Difference between the Coefficients of Variation

Here, three approaches of Niwitpong (2015) are briefly discussed to construct the confidence intervals for the difference of coefficients of variation of normal distributions. The 100(1- $\alpha) \%$ two-sided confidence intervals for the difference of coefficients of variation based on two approaches of Mahmoudvand and Hassani (2009) are defined by

$$
C I_{\delta . M H 1}=\left[\hat{\theta}_{X}-\hat{\theta}_{Y}-z_{1-\alpha / 2} \sqrt{V_{\delta . M H 1}}, \hat{\theta}_{X}-\hat{\theta}_{Y}+z_{1-\alpha / 2} \sqrt{V_{\delta . M H 1}}\right]
$$

and

$$
C I_{\delta . M H 2}=\left[\hat{\theta}_{X}-\hat{\theta}_{Y}-z_{1-\alpha / 2} \sqrt{V_{\delta . M H 2}}, \hat{\theta}_{X}-\hat{\theta}_{Y}+z_{1-\alpha / 2} \sqrt{V_{\delta . M H 2}}\right],
$$

where

$$
V_{\delta . M H 1}=\frac{\widetilde{\theta}_{X}^{2}\left(1-c_{n}^{2}\right)}{2-c_{n}^{2}}+\frac{\widetilde{\theta}_{Y}^{2}\left(1-c_{m}^{2}\right)}{2-c_{m}^{2}}
$$

and

$$
V_{\delta . M H 2}=\frac{\widetilde{\theta}_{X}^{2}\left(2-c_{n}^{2}\right)+\widetilde{\theta}_{X}^{4} / n}{\left(2-c_{n}\right)^{2}}+\frac{\widetilde{\theta}_{Y}^{2}\left(2-c_{m}^{2}\right)+\widetilde{\theta}_{Y}^{4} / m}{\left(2-c_{m}\right)^{2}} .
$$

MOVER Approach for Confidence Interval for the Difference between the Coefficients of Variation

The 100(1- $\alpha) \%$ two-sided confidence interval for the difference of coefficients of variation based on MOVER approach is defined by

$$
\begin{aligned}
C I_{\text {S.MOVER }}= & {\left[\hat{\theta}_{X}-\hat{\theta}_{Y}-\sqrt{\left(\hat{\theta}_{X}-l_{X}\right)^{2}+\left(u_{Y}-\hat{\theta}_{Y}\right)^{2}},\right.} \\
& \left.\hat{\theta}_{X}-\hat{\theta}_{Y}+\sqrt{\left(u_{X}-\hat{\theta}_{X}\right)^{2}+\left(\hat{\theta}_{Y}-l_{Y}\right)^{2}}\right],
\end{aligned}
$$

where

$$
\begin{aligned}
& l_{X}=\frac{S_{X}}{d_{X}}\left(\bar{X}-\sqrt{\max \left(0, \bar{X}^{2}+a_{X} d_{X}\left(a_{X}-2\right)\right)}\right), \\
& l_{Y}=\frac{S_{Y}}{d_{Y}}\left(\bar{Y}-\sqrt{\max \left(0, \bar{Y}^{2}+a_{Y} d_{Y}\left(a_{Y}-2\right)\right)}\right), \\
& u_{X}=\frac{S_{X}}{d_{X}}\left(\bar{X}+\sqrt{\max \left(0, \bar{X}^{2}+b_{X} d_{X}\left(b_{X}-2\right)\right)}\right), \\
& u_{Y}=\frac{S_{Y}}{d_{Y}}\left(\bar{Y}+\sqrt{\max \left(0, \bar{Y}^{2}+b_{Y} d_{Y}\left(b_{Y}-2\right)\right)}\right), \\
& a_{X}=\sqrt{(n-1) / \chi_{1-\alpha / 2, n-1}^{2}}, \\
& a_{Y}=\sqrt{(m-1) / \chi_{1-\alpha / 2, m-1}^{2}}, \\
& b_{X}=\sqrt{(n-1) / \chi_{\alpha / 2, n-1}^{2}}, \\
& b_{Y}=\sqrt{(m-1) / \chi_{\alpha / 2, m-1}^{2}}, \\
& d_{X}=\bar{X}^{2}-z_{\alpha / 2} S_{X}^{2} / n,
\end{aligned}
$$

and

$$
d_{Y}=\bar{Y}^{2}-z_{\alpha / 2} S_{Y}^{2} / m
$$


GCI approach for Confidence Interval for the Difference between the Coefficients of Variation

The GCI approach of Liu et al. (2015) is used to estimate confidence interval for the difference of coefficients of variation of normal distributions. The generalized pivotal quantities for $\theta_{X}$ and $\theta_{Y}$ are defined as

$$
\begin{aligned}
& R_{\theta_{X}}=\frac{\sqrt{(n-1) s_{X}^{2} / \chi_{n-1}^{2}}}{\bar{x}-Z_{X} \sqrt{(n-1) s_{X}^{2} / n \chi_{n-1}^{2}}} \text { and } \\
& R_{\theta_{Y}}=\frac{\sqrt{(m-1) s_{Y}^{2} / \chi_{m-1}^{2}}}{\bar{y}-Z_{Y} \sqrt{(m-1) s_{Y}^{2} / m \chi_{m-1}^{2}}},
\end{aligned}
$$

where $Z_{X}$ and $Z_{Y}$ are the standard normal distributions, $\chi_{n-1}^{2}$ is the chi-square distribution with $n-1$ degrees of freedom, and $\chi_{m-1}^{2}$ is the chi-square distribution with $m-1$ degrees of freedom.

The generalized pivotal quantity for $\delta=\theta_{X}-\theta_{Y}$ is defined as

$$
R_{\delta}=R_{\theta_{X}}-R_{\theta_{Y}} .
$$

Therefore, the 100(1- $\alpha) \%$ two-sided confidence interval for the difference of coefficients of variation based on the GCI approach is obtained by

$$
C I_{\delta . G C I}=\left[L_{\delta . G C I}, U_{\delta . G C I}\right]=\left[R_{\delta}(\alpha / 2), R_{\delta}(1-\alpha / 2)\right],
$$

where $R_{\delta}(\alpha / 2)$ and $R_{\delta}(1-\alpha / 2)$ are the $100(\alpha / 2)$-th and the $100(1-\alpha / 2)$-th percentiles of $R_{\delta}$, respectively.

\section{PROPOSED APPROACH FOR THE DIFFERENCE BETWEEN THE COEFFICIENTS OF VARIATION}

Adjusted GCI Approach for the Difference between the Coefficients of Variation

The GCI approach uses the generalized pivotal quantity for $\delta=\theta_{X}-\theta_{Y}$ to construct the confidence interval for difference of coefficients of variation. The GCI approach is applied the concept of constructing the confidence interval which is the adjusted GCI approach. The adjusted GCI approach uses the generalized pivotal quantity for $\widetilde{\delta}=\widetilde{\theta}_{X}-\widetilde{\theta}_{Y}$ to construct the confidence interval.

From (6), the generalized pivotal quantities for $\widetilde{\theta}_{X}$ and $\widetilde{\theta}_{Y}$ are defined as

$$
R_{\widetilde{\theta}_{X}}=\frac{R_{\theta_{X}}}{2-c_{n}}=\frac{1}{\left(2-c_{n}\right)}\left(\frac{\sqrt{(n-1) s_{X}^{2} / \chi_{n-1}^{2}}}{\bar{x}-Z_{X} \sqrt{(n-1) s_{X}^{2} / n \chi_{n-1}^{2}}}\right)
$$

and

$$
R_{\widetilde{\theta}_{Y}}=\frac{R_{\theta_{Y}}}{2-c_{m}}=\frac{1}{\left(2-c_{m}\right)}\left(\frac{\sqrt{(m-1) s_{Y}^{2} / \chi_{m-1}^{2}}}{\bar{y}-Z_{Y} \sqrt{(m-1) s_{Y}^{2} / m \chi_{m-1}^{2}}}\right)
$$

The generalized pivotal quantity for $\widetilde{\delta}=\widetilde{\theta}_{X}-\widetilde{\theta}_{Y}$ is defined as

$$
R_{\widetilde{\delta}}=R_{\widetilde{\theta}_{X}}-R_{\widetilde{\theta}_{Y}}
$$

Therefore, the $100(1-\alpha) \%$ two-sided confidence interval for the difference of coefficients of variation based on the adjusted GCI approach is obtained by

$$
C I_{\delta . A G C I}=\left[L_{\delta . A G C I}, U_{\delta . A G C I}\right]=\left[R_{\tilde{\delta}}(\alpha / 2), R_{\widetilde{\delta}}(1-\alpha / 2)\right],
$$

where $R_{\widetilde{\delta}}(\alpha / 2)$ and $R_{\widetilde{\delta}}(1-\alpha / 2)$ are the $100(\alpha / 2)$-th and the $100(1-\alpha / 2)$-th percentiles of $R_{\widetilde{\delta}}$, respectively.

The following algorithm is used to construct the adjusted generalized confidence interval for the difference of coefficients of variation of normal distributions:

\section{Algorithm 5}

Step 1: Generate $\chi_{n-1}^{2}, \chi_{m-1}^{2}, Z_{X}$, and $Z_{Y}$; Step 2: Compute $R_{\widetilde{\theta}_{X}}$ from equation (25) and $R_{\widetilde{\theta}_{Y}}$ from (26); Step 3: Compute $R_{\widetilde{\delta}}$ from (27) ; Step 4: Repeat step 1 step 3, a total $q$ times and obtain an array of $R_{\widetilde{\delta}}$ 's; and Step 5: Compute $R_{\widetilde{\delta}}(\alpha / 2)$ and $R_{\widetilde{\delta}}(1-\alpha / 2)$.

Computational Approach for the Difference between the Coefficients of Variation

Let $X_{R M L}=\left(X_{1, R M L}, X_{2 . R M L}, \ldots, X_{n . R M L}\right)$ and $Y_{R M L}=\left(Y_{1 . R M L}, Y_{2 . R M L}, \ldots, Y_{m . R M L}\right)$ be artificial samples from two normal distributions with means $\hat{\mu}_{X . R M L}=\bar{X}$, $\hat{\mu}_{Y_{i} R M L}=\bar{Y}$ and variances $\hat{\sigma}_{X . R M L}^{2}=(n-1) S_{X}^{2} / n$, $\hat{\sigma}_{Y . R M L}^{2}=(m-1) S_{Y}^{2} / m$. Let $\bar{X}_{R M L}$ and $S_{X . R M L}^{2}$ be sample mean and sample variance of $X_{R M L}$, respectively, let $\bar{Y}_{R M L}$ and $S_{Y . R M L}^{2}$ be sample mean and sample variance of $Y_{R M L}$, respectively. Also, let $\bar{x}_{R M L}, \bar{y}_{R M L}, s_{X . R M L}^{2}$, and $s_{Y . R M L}^{2}$ be observed values of $\bar{X}_{R M L}, \bar{Y}_{R M L}, S_{X . R M L}^{2}$, and $S_{Y . R M L}^{2}$, respectively.

The estimator of $\delta_{R M L}=\theta_{X . R M L}-\theta_{Y . R M L}$ is defined as

$$
\hat{\delta}_{R M L}=\hat{\theta}_{X . R M L}-\hat{\theta}_{Y . R M L}=\frac{S_{X . R M L}}{\bar{X}_{R M L}}-\frac{S_{Y . R M L}}{\bar{Y}_{R M L}} .
$$

Therefore, the $100(1-\alpha) \%$ two-sided confidence interval for the difference of coefficients of variation based on the computational approach is obtained by

$$
C I_{\delta . C A}=\left[L_{\delta . C A}, U_{\delta . C A}\right]=\left[\hat{\delta}_{R M L}(\alpha / 2), \hat{\delta}_{R M L}(1-\alpha / 2)\right],
$$

where $\hat{\delta}_{R M L}(\alpha / 2)$ and $\hat{\delta}_{R M L}(1-\alpha / 2)$ are the $100(\alpha / 2)$-th and the $100(1-\alpha / 2)$-th percentiles of $\hat{\delta}_{R M L}$, respectively.

The following algorithm is used to construct the computational confidence interval for the difference of coefficients of variation of normal distributions: 


\section{Algorithm 6}

Step 1: Generate $x_{R M L}$ from $N\left(\hat{\mu}_{X . R M L}, \hat{\sigma}_{X . R M L}^{2}\right)$ and generate $y_{R M L}$ from $N\left(\hat{\mu}_{Y . R M L}, \hat{\sigma}_{Y . R M L}^{2}\right)$; Step 2: Compute $\bar{x}_{R M L}, \bar{y}_{R M L}, s_{X . R M L}^{2}$, and $s_{Y . R M L}^{2}$; Step 3: Compute $\delta_{R M L}$ from (29); Step 4: Repeat step 1 - step 3, a total $q$ times and obtain an array of $\hat{\delta}_{R M L}$ 's; and Step 5: Compute $\hat{\delta}_{R M L}(\alpha / 2)$ and $\hat{\delta}_{R M L}(1-\alpha / 2)$.

Bayesian Approach for the Difference between the Coefficients of Variation

From (12), the posterior distribution of $\delta=\theta_{X}-\theta_{Y}$ is defined as

$$
\delta_{B S}=\frac{\sigma_{X}}{\mu_{X}}-\frac{\sigma_{Y}}{\mu_{Y}} .
$$

Therefore, the 100(1- $\alpha) \%$ two-sided confidence interval for the difference of coefficients of variation based on the Bayesian approach is obtained by

$$
C I_{\delta . B S}=\left[L_{\delta . B S}, U_{\delta . B S}\right],
$$

where $L_{\delta . B S}$ and $U_{\delta . B S}$ are the lower limit and the upper limit of the shortest $100(1-\alpha) \%$ highest posterior density interval of $\delta_{B S}$, respectively.

The following algorithm is used to construct the Bayesian confidence interval for the difference of coefficients of variation of normal distributions:

\section{Algorithm 7}

Step 1: Generate $\sigma_{X}^{2} \mid x \sim I G\left(v_{X} / 2, v_{X} s_{X}^{2} / 2\right)$ and $\sigma_{Y}^{2} \mid y \sim I G$ '( $\left.v_{Y} / 2, v_{Y} s_{Y}^{2} / 2\right)$; Step2: Generate $\mu_{X} \mid \sigma_{X}^{2}, x \sim N\left(\hat{\mu}_{X}, \sigma_{X}^{2} / n\right)$ and $\mu_{Y} \mid \sigma_{Y}^{2}, y \sim N\left(\hat{\mu}_{Y}, \sigma_{Y}^{2} / m\right)$; Step 3: Compute $\delta_{B S}$ from (31) ; Step 4: Repeat step 1 - step 3, a total $q$ times and obtain an array of $\delta_{B S}$ 's; and Step 5: Compute $L_{\delta . B S}$ and $U_{\delta . B S}$.

Adjusted Bayesian Approach for the Difference between the Coefficients of Variation

The concept of Bayesian approach is applied to construct the confidence interval. It is called the adjusted Bayesian approach. The adjusted Bayesian approach uses $R_{\delta}$ in (23). Therefore, the $100(1-\alpha) \%$ two-sided confidence interval for the difference of coefficients of variation based on the adjusted Bayesian approach using the GCI approach based on the generalized pivotal quantity in (23) is obtained by

$$
C I_{\delta . A B S 1}=\left[L_{\delta . A B S 1}, U_{\delta . A B S 1}\right]
$$

where $L_{\delta . A B S 1}$ and $U_{\delta . A B S 1}$ are the lower limit and the upper limit of the shortest $100(1-\alpha) \%$ highest posterior density interval of $R_{\delta}$, respectively.
Similarly, the generalized pivotal quantity $R_{\widetilde{\delta}}$ in (27) is used to construct the adjusted Bayesian confidence interval. Therefore, the $100(1-\alpha) \%$ two-sided confidence interval for the difference of coefficients of variation based on the adjusted Bayesian approach using the adjusted GCI approach based on the generalized pivotal quantity in (27) is obtained by

$$
C I_{\delta . A B S 2}=\left[L_{\delta . A B S 2}, U_{\delta . A B S 2}\right],
$$

where $L_{\delta . A B S 2}$ and $U_{\delta . A B S 2}$ are the lower limit and the upper limit of the shortest $100(1-\alpha) \%$ highest posterior density interval of $R_{\widetilde{\delta}}$, respectively.

The following algorithm is used to construct the adjusted Bayesian confidence interval for the difference of coefficients of variation of normal distributions:

Algorithm 8

Step 1: Generate $\chi_{n-1}^{2}, \chi_{m-1}^{2}, Z_{X}$, and $Z_{Y}$; Step 2: Compute $R_{\theta_{X}}$ and $R_{\theta_{Y}}$ from (22); Step 3: Compute $R_{\widetilde{\theta}_{X}}$ from (25) and $R_{\widetilde{\theta}_{Y}}$ from (26); Step 4: Compute $R_{\delta}$ from (23) and compute $R_{\widehat{\delta}}$ from (27); Step 5: Repeat step 1 - step 4, a total $q$ times and obtain array of $R_{\delta}$ 's and array of $R_{\widetilde{\delta}}$ 's; Step 6: Compute $L_{\delta . A B S 1}$; Step 7: Compute $U_{\delta . A B S 1}$; Step 8: Compute $L_{\delta . A B S 2}$; and Step 9: Compute $U_{\delta . A B S 2}$.

\section{SIMULATION STUDIES}

Monte Carlo simulation studies were carried out to evaluate the performance of the proposed confidence intervals for the coefficient of variation of a normal distribution and the difference between the coefficients of variation of two normal distributions. Then, it is used to conduct a comparison study with the proposed and existing confidence intervals. The proposed confidence intervals for both scenarios were constructed using the adjusted GCI, computational, Bayesian, and two adjusted Bayesian approaches, while the existing ones were constructed based on two approximately unbiased estimators, MOVER, and GCI. Moreover, for the difference of coefficients of variation, three existing confidence intervals proposed by Niwitpong (2015) and the GCI were used in the study. The performances of these approaches were evaluated through the coverage probabilities and average lengths of the confidence intervals. 5000 simulation datasets were generated for each parameter combination and 2500 random variables were generated to construct the confidence intervals for each dataset.

The following algorithm is used to compute the coverage probability and average length of the confidence interval for single coefficient of variation of a normal distribution: 
Algorithm 9

Step 1: Generate $x$ from $N\left(\mu, \sigma^{2}\right)$; Step 2: Compute $\bar{x}$ and $s^{2}$; Step 3: Use algorithm 1 - algorithm 4 to construct the confidence intervals; Step 4: If $L \leq \theta \leq U$, set $p=$ 1; else set $p=0$; Step 5: Compute $U-L$; Step 6: Repeat step 1 - step 5, a total $M$ times; Step 7: Compute mean of $p$ defined by the coverage probability; and Step 8: Compute mean of $U-L$ defined by the average length.

The following algorithm is used to compute the coverage probability and average length of the confidence interval for the difference between the coefficients of variation of two normal distributions:

\section{Algorithm 10}

Step 1: Generate $x$ from $N\left(\mu_{X}, \sigma_{X}^{2}\right)$ and generate $y$ from $N\left(\mu_{Y}, \sigma_{Y}^{2}\right)$; Step 2: Compute $\bar{x}, \bar{y}, s_{X}^{2}$, and $s_{Y}^{2}$; Step 3: Use algorithm 5 - algorithm 8 to construct the confidence intervals;

Step 4: If $L \leq \delta \leq U$, set $p=1$; else set $p=0$; Step 5: Compute $U-L$; Step 6: Repeat step 1 - step 5, a total $M$ times; Step 7: Compute mean of $p$ defined by the coverage probability; and Step 8: Compute mean of $U-L$ defined by the average length.
The performances of the confidence intervals for the coefficient of variation of a normal distribution are compared in Table 2 . For a very small sample size $(n=$ $10)$, the coverage probabilities of the GCI and adjusted GCI approaches were close to the nominal confidence level of 0.95 when the coefficient of variation was small $(\theta \leq 0.50)$ but were unsatisfactory when it was large $(\theta>0.50)$. Moreover, these approaches attained coverage probabilities close to the nominal confidence level of 0.95 with increasing sample size. However, the coverage probabilities of the confidence intervals via the computational approach were quite unsatisfactory whereas those with Bayesian and two adjusted Bayesian approaches were very satisfactory for all cases. Indeed, the three Bayesian approaches performed consistently better than the three existing approaches. The results confirm that the Bayesian and two adjusted Bayesian approaches performed well in terms of coverage probability and average length for almost all cases whereas the GCI and the adjusted GCI approaches were better when the coefficient of variation was small $(\theta \leq 0.50)$. The Bayesian approach and two adjusted Bayesian approaches are recommended when the coefficient of variation is large $(\theta>0.50)$.

TABLE 2. Coverage probabilities and average lengths of $95 \%$ two-sided confidence intervals for the coefficient of variation of normal distribution

\begin{tabular}{|c|c|c|c|c|c|}
\hline \multirow{3}{*}{$n$} & \multirow{3}{*}{$\begin{array}{l}\text { Confidence } \\
\text { intervals }\end{array}$} & \multicolumn{4}{|c|}{ Coverage probability (Average length) } \\
\hline & & \multicolumn{4}{|c|}{$\theta$} \\
\hline & & 0.05 & 0.10 & 0.50 & 1.00 \\
\hline \multirow[t]{9}{*}{10} & $C I_{\theta . M H 1}$ & $\begin{array}{c}0.9408 \\
(0.0525)\end{array}$ & $\begin{array}{c}0.9442 \\
(0.1041)\end{array}$ & $\begin{array}{c}0.8904 \\
(0.5376)\end{array}$ & $\begin{array}{c}0.7580 \\
(1.2152)\end{array}$ \\
\hline & $C I_{\theta . M H 2}$ & $\begin{array}{c}0.8650 \\
(0.0423)\end{array}$ & $\begin{array}{c}0.8674 \\
(0.0845)\end{array}$ & $\begin{array}{c}0.8708 \\
(0.5383)\end{array}$ & $\begin{array}{c}0.8492 \\
(2.8621)\end{array}$ \\
\hline & $C I_{\theta . M O V E R}$ & $\begin{array}{c}0.9374 \\
(0.0555)\end{array}$ & $\begin{array}{c}0.9366 \\
(0.1091)\end{array}$ & $\begin{array}{c}0.8104 \\
(0.4704)\end{array}$ & $\begin{array}{c}0.8668 \\
(0.7176)\end{array}$ \\
\hline & $C I_{\theta . G C I}$ & $\begin{array}{c}0.9412 \\
(0.0559)\end{array}$ & $\begin{array}{c}0.9488 \\
(0.1124)\end{array}$ & $\begin{array}{c}0.9500 \\
(0.9005)\end{array}$ & $\begin{array}{c}0.9770 \\
(8.3653)\end{array}$ \\
\hline & $C I_{\theta . A G C I}$ & $\begin{array}{c}0.9470 \\
(0.0544)\end{array}$ & $\begin{array}{c}0.9516 \\
(0.1094)\end{array}$ & $\begin{array}{c}0.9502 \\
(0.8772)\end{array}$ & $\begin{array}{c}0.9752 \\
(8.1844)\end{array}$ \\
\hline & $C I_{\theta . C A}$ & $\begin{array}{c}0.8514 \\
(0.0422)\end{array}$ & $\begin{array}{c}0.8574 \\
(0.0843)\end{array}$ & $\begin{array}{c}0.8766 \\
(0.5796)\end{array}$ & $\begin{array}{c}0.8926 \\
(5.5239)\end{array}$ \\
\hline & $C I_{\theta . B S}$ & $\begin{array}{c}0.9450 \\
(0.0513)\end{array}$ & $\begin{array}{c}0.9496 \\
(0.1029)\end{array}$ & $\begin{array}{c}0.9526 \\
(0.7460)\end{array}$ & $\begin{array}{c}0.9534 \\
(7.6017)\end{array}$ \\
\hline & $C I_{\theta . A B S 1}$ & $\begin{array}{c}0.9448 \\
(0.0514)\end{array}$ & $\begin{array}{c}0.9492 \\
(0.1029)\end{array}$ & $\begin{array}{c}0.9538 \\
(0.7454)\end{array}$ & $\begin{array}{c}0.9544 \\
(7.5586)\end{array}$ \\
\hline & $C I_{\theta . A B S 2}$ & $\begin{array}{c}0.9380 \\
(0.0500)\end{array}$ & $\begin{array}{c}0.9442 \\
(0.1001)\end{array}$ & $\begin{array}{c}0.9466 \\
(0.7258)\end{array}$ & $\begin{array}{c}0.9472 \\
(7.3775)\end{array}$ \\
\hline
\end{tabular}


$(0.0267)$

0.9486

0.8894

$(0.2696)$

0.7440

$C I_{\theta . M H 2}$

0.9232

$(0.0534)$

0.9268

$(0.3105)$

(0.5544)

$C I_{\theta \text { MOVER }}$

0.9480

(0.0504)

0.6960

0.9114

0.9282

$(0.0270)$

$(0.0534)$

$(0.2153)$

$(0.9462)$

$C I_{\theta \cdot G C l}$

$(0.0273)$

0.9504

0.9444

0.5360

$(0.0550)$

$(0.3549)$

(0.3532)

0.9520

0.9530

0.9482

(1.3274)

$C I_{\theta . A G C I}$

$(0.0270)$

$(0.0545)$

(0.3518)

0.9498

0.9134

0.9268

(1.3140)

$C I_{\theta . C A}$

$(0.0250)$

(0.0504)

$(0.3154)$

0.9304

0.9472

0.9522

(1.1205)

$C I_{\theta, B S}$

$(0.0264)$

$(0.0532)$

(0.3358)

0.9580

(1.1451)

$C I_{\theta . A B S 1}$

0.9480

0.9536

0.9592

$(0.0264)$

$(0.0532)$

$(0.3360)$

(1.1460)

$C I_{\theta . A B S 2}$

0.9456

0.9506

0.9538

0.9486
$(0.0262)$

$(0.0528)$

$(0.3331)$

(1.1368)

0.9486

0.9428

$C I_{\theta . M H 1}$

$(0.0203)$

$(0.0404)$

0.8864

0.7460

$C I_{\theta . M H 2}$

0.9372

(0.0195)

0.9316

(0.2031)

(0.4130)

$C I_{\theta \text { MOVER }}$

0.9446

(0.0204)

$(0.0392)$

0.9282

0.9234

$(0.2397)$

(0.7069)

0.9114

$(0.0394)$

0.6398

0.4880

$(0.1661)$

$(0.2925)$

$C I_{\theta \cdot G C I}$

0.9448

$(0.0205)$

$(0.0412)$

0.9430

$(0.2590)$

0.9504

$C I_{\theta . A G C I}$

0.9480

0.9452

$(0.8332)$

0.9522

$(0.0204)$

$(0.0410)$

$(0.2577)$

0.9494

$C I_{\theta . C A}$

0.9282

0.9260

$(0.8290)$

$(0.0195)$

(0.0392)

$(0.2420)$

0.9356

(0.7621)

$C I_{\theta \cdot B S}$

0.9434

0.9424

0.9522

$(0.0201)$

$(0.0403)$

$(0.2501)$

(0.7714)

$C I_{\theta . A B S 1}$

0.9434

0.9436

0.9518

$(0.0201)$

$(0.2501)$

(0.7711)

$C I_{\theta . A B S 2}$

0.9438

0.9456
$(0.0200)$

0.9434

0.9520

$(0.0401)$

$(0.2489)$

$(0.7675)$

0.9522

0.9478

0.8850

0.7456

$C I_{\theta . M H 1}$

$(0.0282)$

$(0.1412)$

$(0.2850)$

$C I_{\theta . M H 2}$

0.9404

0.9364

0.9426

$(0.0138)$

$(0.0279)$

$(0.1698)$

(0.4913)

$C I_{\theta . \text { MOVER }}$

0.9388

0.8806

0.5814

0.4926

$(0.0269)$

(0.1195)

$(0.2506)$

$C I_{\theta \cdot G C I}$

0.9512

$(0.0142)$

0.9478

0.9434

0.9452

$(0.0286)$

$(0.1763)$

$(0.5293)$

$C I_{\theta . A G C I}$

0.9524

0.9498

0.9456

0.9464

$(0.0285)$

$(0.1759)$

(0.5282)

$C I_{\theta . C A}$

0.9426

$(0.0138)$

0.9372

0.9366

0.9424

$(0.0279)$

$(0.1705)$

$(0.5075)$

$C I_{\theta . B S}$

0.9504

0.9456

0.9424

0.9514

(0.0140)

$(0.0282)$

(0.1726)

(0.5088)

$C I_{\theta . A B S 1}$

0.9460

0.9438

0.9506

$(0.0140)$

$(0.0282)$

$(0.1727)$

$(0.5087)$

$C I_{\theta \cdot A B S 2}$

0.9500

0.9456

0.9446
$(0.1722)$

0.9508

$(0.0281)$

$(0.1722)$

$(0.5076)$ 
200

$\begin{array}{cc}C I_{\theta . M H 1} & 0.9536 \\ & (0.0099) \\ C I_{\theta . M H 2} & 0.9492 \\ & (0.0098) \\ C I_{\theta . M O V E R} & 0.9210 \\ & (0.0097) \\ C I_{\theta . G C I} & 0.9538 \\ & (0.0099) \\ C I_{\theta . A G C I} & 0.9544 \\ & (0.0099) \\ C I_{\theta . C A} & 0.9476 \\ & (0.0098) \\ C I_{\theta . B S} & 0.9514 \\ & (0.0098) \\ C I_{\theta . A B S 1} & 0.9514 \\ C I_{\theta . A B S 2} & (0.0098) \\ & 0.9492 \\ & (0.0098)\end{array}$

0.9516

(0.0198)

0.9514

(0.0198)

0.8246

(0.0182)

0.9552

(0.0200)

0.9544

(0.0200)

0.9492

(0.0198)

0.9546

(0.0198)

0.9514

(0.0198)

0.9524

(0.0198)

$\begin{array}{cc}0.8926 & 0.7404 \\ (0.0988) & (0.1985) \\ 0.9444 & 0.9458 \\ (0.1199) & (0.3427) \\ 0.5580 & 0.4938 \\ (0.0938) & (0.2095) \\ 0.9498 & 0.9518 \\ (0.1222) & (0.3551) \\ 0.9510 & 0.9508 \\ (0.1221) & (0.3547) \\ 0.9470 & 0.9484 \\ (0.1202) & (0.3480) \\ 0.9486 & 0.9500 \\ (0.1205) & (0.3471) \\ 0.9480 & 0.9520 \\ (0.1205) & (0.3471) \\ 0.9474 & 0.9498 \\ (0.1203) & (0.3466)\end{array}$

The coverage probabilities and the average lengths of the $95 \%$ two-sided confidence intervals for the difference between the coefficients of variation of two normal distributions are reported in Table 3. For small sample sizes $(n, m)=(10,10)$ and $(n, m)=(10,30)$, the GCI, adjusted GCI, Bayesian, and two adjusted Bayesian approaches yielded coverage probabilities that tended to be too high as compared to the nominal confidence level of 0.95 when the coefficients of variation were large. However, these approaches performed well with coverage probabilities that were close to the nominal confidence level of 0.95 when the sample sizes were large. Meanwhile, the computational approach and three existing approaches tended to underestimate the coverage probabilities when the sample sizes were small but became closer to the nominal confidence level of 0.95 as the sample sizes increased. Furthermore, the average lengths of the Bayesian approach and two adjusted Bayesian approaches were shorter than those of the GCI approach and adjusted GCI approaches, and it was found that the two adjusted Bayesian approaches performed better than the others when the coefficients of variation were small. Meanwhile, the two approximately unbiased estimators of Mahmoudvand and Hassani (2009) were better than the other approaches when the coefficients of variation were large.

TABLE 3. Coverage probabilities and average lengths of $95 \%$ two-sided confidence intervals for the difference of coefficients of variation of normal distributions

\begin{tabular}{|c|c|c|c|c|c|c|}
\hline \multirow{3}{*}{$n$} & \multirow{3}{*}{$m$} & \multirow{3}{*}{$\begin{array}{c}\text { Confidence } \\
\text { intervals }\end{array}$} & \multicolumn{4}{|c|}{ Coverage probability (Average length) } \\
\hline & & & \multicolumn{4}{|c|}{$\left(\theta_{X}, \theta_{Y}\right)$} \\
\hline & & & $(0.05,0.05)$ & $(0.20,0.30)$ & $(0.55,0.55)$ & $(0.90,0.75)$ \\
\hline \multirow[t]{5}{*}{10} & 10 & $C I_{\delta . M H 1}$ & $\begin{array}{c}0.9312 \\
(0.0604)\end{array}$ & $\begin{array}{c}0.9170 \\
(0.3079)\end{array}$ & $\begin{array}{c}0.8756 \\
(0.6884)\end{array}$ & $\begin{array}{c}0.7782 \\
(1.1206)\end{array}$ \\
\hline & & $C I_{\delta . M H 2}$ & $\begin{array}{c}0.9318 \\
(0.0605)\end{array}$ & $\begin{array}{c}0.9342 \\
(0.3306)\end{array}$ & $\begin{array}{c}0.9826 \\
(0.9068)\end{array}$ & $\begin{array}{c}0.9860 \\
(2.2424)\end{array}$ \\
\hline & & $C I_{\delta . M O V E R}$ & $\begin{array}{c}0.9492 \\
(0.0865)\end{array}$ & $\begin{array}{c}0.9222 \\
(0.4109)\end{array}$ & $\begin{array}{c}0.9082 \\
(0.8024)\end{array}$ & $\begin{array}{c}0.9098 \\
(1.2799)\end{array}$ \\
\hline & & $C I_{\delta . G C I}$ & $\begin{array}{c}0.9442 \\
(0.0841)\end{array}$ & $\begin{array}{c}0.9498 \\
(0.4873)\end{array}$ & $\begin{array}{c}0.9600 \\
(1.8269)\end{array}$ & $\begin{array}{c}0.9814 \\
(8.5703)\end{array}$ \\
\hline & & $C I_{\delta . A G C I}$ & $\begin{array}{c}0.9442 \\
(0.0817)\end{array}$ & $\begin{array}{c}0.9502 \\
(0.4745)\end{array}$ & $\begin{array}{c}0.9594 \\
(1.7785)\end{array}$ & $\begin{array}{c}0.9804 \\
(8.3088)\end{array}$ \\
\hline
\end{tabular}




\begin{tabular}{|c|c|c|c|c|c|c|}
\hline & & $C I_{\delta . C A}$ & $\begin{array}{c}0.9444 \\
(0.0606)\end{array}$ & $\begin{array}{c}0.9330 \\
(0.3349)\end{array}$ & $\begin{array}{c}0.9472 \\
(1.0536)\end{array}$ & $\begin{array}{c}0.9548 \\
(4.8625)\end{array}$ \\
\hline & & $C I_{\delta . B S}$ & $\begin{array}{c}0.9618 \\
(0.0827)\end{array}$ & $\begin{array}{c}0.9676 \\
(0.4713)\end{array}$ & $\begin{array}{c}0.9882 \\
(1.7195)\end{array}$ & $\begin{array}{c}0.9952 \\
(8.2006)\end{array}$ \\
\hline & & $C I_{\delta . A B S 1}$ & $\begin{array}{c}0.9610 \\
(0.0827)\end{array}$ & $\begin{array}{c}0.9678 \\
(0.4712)\end{array}$ & $\begin{array}{c}0.9886 \\
(1.7193)\end{array}$ & $\begin{array}{c}0.9948 \\
(8.2057)\end{array}$ \\
\hline & & $C I_{\delta . A B S 2}$ & $\begin{array}{c}0.9616 \\
(0.0805)\end{array}$ & $\begin{array}{c}0.9680 \\
(0.4581)\end{array}$ & $\begin{array}{c}0.9882 \\
(1.6782)\end{array}$ & $\begin{array}{c}0.9948 \\
(7.9864)\end{array}$ \\
\hline \multirow[t]{9}{*}{10} & 30 & $C I_{\delta . M H 1}$ & $\begin{array}{c}0.9148 \\
(0.0491)\end{array}$ & $\begin{array}{c}0.9244 \\
(0.2287)\end{array}$ & $\begin{array}{c}0.8618 \\
(0.5613)\end{array}$ & $\begin{array}{c}0.7552 \\
(0.9335)\end{array}$ \\
\hline & & $C I_{\delta . M H 2}$ & $\begin{array}{c}0.9152 \\
(0.0492)\end{array}$ & $\begin{array}{c}0.9442 \\
(0.2429)\end{array}$ & $\begin{array}{c}0.9338 \\
(0.7318)\end{array}$ & $\begin{array}{c}0.9092 \\
(1.8908)\end{array}$ \\
\hline & & $C I_{\delta . M O V E R}$ & $\begin{array}{c}0.9468 \\
(0.0643)\end{array}$ & $\begin{array}{c}0.9174 \\
(0.2796)\end{array}$ & $\begin{array}{c}0.8756 \\
(0.6209)\end{array}$ & $\begin{array}{c}0.9090 \\
(1.0677)\end{array}$ \\
\hline & & $C I_{\delta . G C I}$ & $\begin{array}{c}0.9480 \\
(0.0637)\end{array}$ & $\begin{array}{c}0.9476 \\
(0.3150)\end{array}$ & $\begin{array}{c}0.9562 \\
(1.2545)\end{array}$ & $\begin{array}{c}0.9732 \\
(5.9170)\end{array}$ \\
\hline & & $C I_{\delta . A G C I}$ & $\begin{array}{c}0.9486 \\
(0.0623)\end{array}$ & $\begin{array}{c}0.9474 \\
(0.3091)\end{array}$ & $\begin{array}{c}0.9562 \\
(1.2276)\end{array}$ & $\begin{array}{c}0.9706 \\
(5.8039)\end{array}$ \\
\hline & & $C I_{\delta . C A}$ & $\begin{array}{c}0.9092 \\
(0.0492)\end{array}$ & $\begin{array}{c}0.9402 \\
(0.2445)\end{array}$ & $\begin{array}{c}0.9192 \\
(0.8131)\end{array}$ & $\begin{array}{c}0.9078 \\
(3.7768)\end{array}$ \\
\hline & & $C I_{\delta . B S}$ & $\begin{array}{c}0.9560 \\
(0.0613)\end{array}$ & $\begin{array}{c}0.9628 \\
(0.3070)\end{array}$ & $\begin{array}{c}0.9734 \\
(1.1197)\end{array}$ & $\begin{array}{c}0.9710 \\
(5.4093)\end{array}$ \\
\hline & & $C I_{\delta . A B S 1}$ & $\begin{array}{c}0.9578 \\
(0.0613)\end{array}$ & $\begin{array}{c}0.9634 \\
(0.3070)\end{array}$ & $\begin{array}{c}0.9716 \\
(1.1186)\end{array}$ & $\begin{array}{c}0.9702 \\
(5.4105)\end{array}$ \\
\hline & & $C I_{\delta . A B S 2}$ & $\begin{array}{c}0.9552 \\
(0.0600)\end{array}$ & $\begin{array}{c}0.9646 \\
(0.3014)\end{array}$ & $\begin{array}{c}0.9694 \\
(1.0942)\end{array}$ & $\begin{array}{c}0.9694 \\
(5.3039)\end{array}$ \\
\hline \multirow[t]{9}{*}{30} & 30 & $C I_{\delta . M H 1}$ & $\begin{array}{c}0.9446 \\
(0.0354)\end{array}$ & $\begin{array}{c}0.9254 \\
(0.1816)\end{array}$ & $\begin{array}{c}0.8832 \\
(0.3952)\end{array}$ & $\begin{array}{c}0.7908 \\
(0.6063)\end{array}$ \\
\hline & & $C I_{\delta . M H 2}$ & $\begin{array}{c}0.9452 \\
(0.0355)\end{array}$ & $\begin{array}{c}0.9448 \\
(0.1949)\end{array}$ & $\begin{array}{c}0.9656 \\
(0.5068)\end{array}$ & $\begin{array}{c}0.9732 \\
(0.9856)\end{array}$ \\
\hline & & $C I_{\text {S.MOVER }}$ & $\begin{array}{c}0.9520 \\
(0.0396)\end{array}$ & $\begin{array}{c}0.8960 \\
(0.1901)\end{array}$ & $\begin{array}{c}0.8710 \\
(0.4139)\end{array}$ & $\begin{array}{c}0.8642 \\
(0.6902)\end{array}$ \\
\hline & & $C I_{\delta \cdot G C I}$ & $\begin{array}{c}0.9492 \\
(0.0393)\end{array}$ & $\begin{array}{c}0.9474 \\
(0.2190)\end{array}$ & $\begin{array}{c}0.9536 \\
(0.6049)\end{array}$ & $\begin{array}{c}0.9468 \\
(1.3273)\end{array}$ \\
\hline & & $C I_{\delta . A G C I}$ & $\begin{array}{c}0.9506 \\
(0.0389)\end{array}$ & $\begin{array}{c}0.9482 \\
(0.2171)\end{array}$ & $\begin{array}{c}0.9532 \\
(0.5994)\end{array}$ & $\begin{array}{c}0.9464 \\
(1.3166)\end{array}$ \\
\hline & & $C I_{\delta . C A}$ & $\begin{array}{c}0.9506 \\
(0.0355)\end{array}$ & $\begin{array}{c}0.9432 \\
(0.1957)\end{array}$ & $\begin{array}{c}0.9522 \\
(0.5221)\end{array}$ & $\begin{array}{c}0.9420 \\
(1.1115)\end{array}$ \\
\hline & & $C I_{\delta, B S}$ & $\begin{array}{c}0.9560 \\
(0.0389)\end{array}$ & $\begin{array}{c}0.9554 \\
(0.2155)\end{array}$ & $\begin{array}{c}0.9698 \\
(0.5959)\end{array}$ & $\begin{array}{c}0.9758 \\
(1.2709)\end{array}$ \\
\hline & & $C I_{\delta . A B S 1}$ & $\begin{array}{c}0.9564 \\
(0.0389)\end{array}$ & $\begin{array}{c}0.9564 \\
(0.2156)\end{array}$ & $\begin{array}{c}0.9704 \\
(0.5957)\end{array}$ & $\begin{array}{c}0.9756 \\
(1.2709)\end{array}$ \\
\hline & & $C I_{\delta . A B S 2}$ & $\begin{array}{c}0.9576 \\
(0.0386)\end{array}$ & $\begin{array}{c}0.9534 \\
(0.2138)\end{array}$ & $\begin{array}{c}0.9688 \\
(0.5909)\end{array}$ & $\begin{array}{c}0.9744 \\
(1.2606)\end{array}$ \\
\hline \multirow[t]{4}{*}{30} & 50 & $C I_{\delta . M H 1}$ & $\begin{array}{c}0.9488 \\
(0.0317)\end{array}$ & $\begin{array}{c}0.9334 \\
(0.1544)\end{array}$ & $\begin{array}{c}0.8754 \\
(0.3537)\end{array}$ & $\begin{array}{c}0.7762 \\
(0.5524)\end{array}$ \\
\hline & & $C I_{\delta . M H 2}$ & $\begin{array}{c}0.9498 \\
(0.0318)\end{array}$ & $\begin{array}{c}0.9522 \\
(0.1649)\end{array}$ & $\begin{array}{c}0.9566 \\
(0.4529)\end{array}$ & $\begin{array}{c}0.9562 \\
(0.9050)\end{array}$ \\
\hline & & $C I_{\delta . M O V E R}$ & $\begin{array}{c}0.9538 \\
(0.0347)\end{array}$ & $\begin{array}{c}0.8984 \\
(0.1605)\end{array}$ & $\begin{array}{c}0.8682 \\
(0.3724)\end{array}$ & $\begin{array}{c}0.8690 \\
(0.6453)\end{array}$ \\
\hline & & $C I_{\delta . G C I}$ & $\begin{array}{c}0.9534 \\
(0.0346)\end{array}$ & $\begin{array}{c}0.9532 \\
(0.1801)\end{array}$ & $\begin{array}{c}0.9500 \\
(0.5243)\end{array}$ & $\begin{array}{c}0.9472 \\
(1.1947)\end{array}$ \\
\hline
\end{tabular}




0.9550
$(0.0343)$
0.9494

0.9514
$(0.1790)$
0.9514

0.9502

0.9498

$C I_{\delta . A G C I}$

(0.0318)

(0.1654)

(0.5207)

(1.1849)

$C I_{\delta . C A}$

0.9584

$C I_{\delta . B S}$

(0.0342)

0.9576

(0.1783)

0.9458

(0.4643)

0.9386

(1.0217)

$C I_{\delta . A B S 1}$

0.9594

0.9584

0.9628

0.9702

(0.5148)

(1.1246)

0.9636

0.9706

(0.0342)

(0.1785)

(0.5148)

(1.1268)

0.9568

0.9570

(0.1772)

0.9600

(0.5108)

0.9694

(1.1165)

0.9504

(0.0276)

0.9270

(0.1408)

0.8744

0.7916

(0.3056)

(0.4643)

$C_{\delta . M H 2}$

0.9508

(0.0276)

0.9448

(0.1511)

0.9546

(0.3900)

0.9662

$C I_{\delta . M O V E R}$

0.9498

(0.0294)

0.8854

(0.1430)

0.8576

(0.3284)

(0.7396)

$C_{\text {S.GCI }}$

0.9484

(0.0293)

(0.1618)

$C I_{\delta . A G C I}$

0.9520

(0.0292)

0.9470

(0.1610)

$C I_{\text {S.CA }}$

0.9502

0.9448

(0.1514)

0.9480

(0.4321)

0.9474

(0.4299)

0.9434

(0.3967)

0.9574

(0.4274)

(0.1597)

0.9560

(0.4274)

(0.1598)

0.9562

(0.4252)

(0.1590)

0.8750

(0.2639)

(0.1140)

0.9540

(0.3360)

0.8524

(0.2925)

0.9518

(0.3647)

0.9528

(0.3633)

0.9464

(0.3406)

0.9570

(0.3592)

0.9578

(0.3594)

0.9596

(0.3579)

0.8812

(0.2158)

0.9542

(0.2744)

0.8662

(0.5597)

0.9462

(0.8669)

0.9484

(0.8627)

0.9440

(0.7851)

0.9662

(0.8492)

0.9662

(0.8487)

0.9650

(0.8438)

0.7864

(0.4135)

0.9520

(0.6663)

0.8698

(0.5093)

0.9524

(0.7652)

0.9534

(0.7611)

0.9450

(0.7026)

0.9662

(0.7389)

0.9666

(0.7389)

0.9650

(0.1260)

(0.7358)

0.9458

(0.0195)

(0.0998)

0.9498

(0.0196)

(0.1070)

0.8566

(0.2472)

0.7866

(0.3265)

0.9608

(0.5137)

0.8624

(0.1006)

0.8688

(0.4322) 


\begin{tabular}{|c|c|c|c|c|c|c|}
\hline & & $C I_{\delta \cdot G C I}$ & $\begin{array}{c}0.9464 \\
(0.0202)\end{array}$ & $\begin{array}{c}0.9500 \\
(0.1107)\end{array}$ & $\begin{array}{c}0.9504 \\
(0.2885)\end{array}$ & $\begin{array}{c}0.9526 \\
(0.5534)\end{array}$ \\
\hline & & $C I_{\delta . A G C I}$ & $\begin{array}{c}0.9460 \\
(0.0201)\end{array}$ & $\begin{array}{c}0.9504 \\
(0.1104)\end{array}$ & $\begin{array}{c}0.9518 \\
(0.2878)\end{array}$ & $\begin{array}{c}0.9514 \\
(0.5524)\end{array}$ \\
\hline & & $C I_{\delta . C A}$ & $\begin{array}{c}0.9454 \\
(0.0196)\end{array}$ & $\begin{array}{c}0.9484 \\
(0.1072)\end{array}$ & $\begin{array}{c}0.9494 \\
(0.2768)\end{array}$ & $\begin{array}{c}0.9500 \\
(0.5277)\end{array}$ \\
\hline & & $C I_{\delta . B S}$ & $\begin{array}{c}0.9450 \\
(0.0200)\end{array}$ & $\begin{array}{c}0.9502 \\
(0.1096)\end{array}$ & $\begin{array}{c}0.9546 \\
(0.2858)\end{array}$ & $\begin{array}{c}0.9620 \\
(0.5467)\end{array}$ \\
\hline & & $C I_{\delta . A B S 1}$ & $\begin{array}{c}0.9460 \\
(0.0200)\end{array}$ & $\begin{array}{c}0.9512 \\
(0.1096)\end{array}$ & $\begin{array}{c}0.9548 \\
(0.2859)\end{array}$ & $\begin{array}{c}0.9612 \\
(0.5466)\end{array}$ \\
\hline & & $C I_{\delta . A B S 2}$ & $\begin{array}{c}0.9462 \\
(0.0200)\end{array}$ & $\begin{array}{c}0.9512 \\
(0.1093)\end{array}$ & $\begin{array}{c}0.9538 \\
(0.2853)\end{array}$ & $\begin{array}{c}0.9622 \\
(0.5453)\end{array}$ \\
\hline \multirow[t]{9}{*}{100} & 200 & $C I_{\delta . M H 1}$ & $\begin{array}{c}0.9498 \\
(0.0169)\end{array}$ & $\begin{array}{c}0.9386 \\
(0.0808)\end{array}$ & $\begin{array}{c}0.8752 \\
(0.1868)\end{array}$ & $\begin{array}{c}0.7744 \\
(0.2914)\end{array}$ \\
\hline & & $C I_{\delta . M H 2}$ & $\begin{array}{c}0.9502 \\
(0.0170)\end{array}$ & $\begin{array}{c}0.9530 \\
(0.0860)\end{array}$ & $\begin{array}{c}0.9498 \\
(0.2373)\end{array}$ & $\begin{array}{c}0.9522 \\
(0.4652)\end{array}$ \\
\hline & & $C I_{\delta . M O V E R}$ & $\begin{array}{c}0.9432 \\
(0.0172)\end{array}$ & $\begin{array}{c}0.8740 \\
(0.0840)\end{array}$ & $\begin{array}{c}0.8590 \\
(0.2243)\end{array}$ & $\begin{array}{c}0.8536 \\
(0.3926)\end{array}$ \\
\hline & & $C I_{\delta, G C I}$ & $\begin{array}{c}0.9530 \\
(0.0174)\end{array}$ & $\begin{array}{c}0.9526 \\
(0.0882)\end{array}$ & $\begin{array}{c}0.9476 \\
(0.2471)\end{array}$ & $\begin{array}{c}0.9512 \\
(0.4965)\end{array}$ \\
\hline & & $C I_{\delta . A G C I}$ & $\begin{array}{c}0.9534 \\
(0.0173)\end{array}$ & $\begin{array}{c}0.9524 \\
(0.0880)\end{array}$ & $\begin{array}{c}0.9470 \\
(0.2465)\end{array}$ & $\begin{array}{c}0.9516 \\
(0.4952)\end{array}$ \\
\hline & & $C I_{\delta . C A}$ & $\begin{array}{c}0.9508 \\
(0.0170)\end{array}$ & $\begin{array}{c}0.9526 \\
(0.0861)\end{array}$ & $\begin{array}{c}0.9460 \\
(0.2389)\end{array}$ & $\begin{array}{c}0.9490 \\
(0.4767)\end{array}$ \\
\hline & & $C I_{\delta . B S}$ & $\begin{array}{c}0.9514 \\
(0.0172)\end{array}$ & $\begin{array}{c}0.9526 \\
(0.0874)\end{array}$ & $\begin{array}{c}0.9504 \\
(0.2444)\end{array}$ & $\begin{array}{c}0.9574 \\
(0.4867)\end{array}$ \\
\hline & & $C I_{\delta . A B S 1}$ & $\begin{array}{c}0.9528 \\
(0.0172)\end{array}$ & $\begin{array}{c}0.9546 \\
(0.0874)\end{array}$ & $\begin{array}{c}0.9502 \\
(0.2442)\end{array}$ & $\begin{array}{c}0.9566 \\
(0.4868)\end{array}$ \\
\hline & & $C I_{\delta . A B S 2}$ & $\begin{array}{c}0.9540 \\
(0.0172)\end{array}$ & $\begin{array}{c}0.9538 \\
(0.0873)\end{array}$ & $\begin{array}{c}0.9516 \\
(0.2438)\end{array}$ & $\begin{array}{c}0.9590 \\
(0.4858)\end{array}$ \\
\hline \multirow[t]{9}{*}{200} & 200 & $C I_{\delta . M H 1}$ & $\begin{array}{c}0.9496 \\
(0.0138)\end{array}$ & $\begin{array}{c}0.9302 \\
(0.0706)\end{array}$ & $\begin{array}{c}0.8774 \\
(0.1526)\end{array}$ & $\begin{array}{c}0.7948 \\
(0.2304)\end{array}$ \\
\hline & & $C I_{\delta . M H 2}$ & $\begin{array}{c}0.9500 \\
(0.0139)\end{array}$ & $\begin{array}{c}0.9476 \\
(0.0757)\end{array}$ & $\begin{array}{c}0.9464 \\
(0.1936)\end{array}$ & $\begin{array}{c}0.9552 \\
(0.3605)\end{array}$ \\
\hline & & $C I_{\text {S.MOVER }}$ & $\begin{array}{c}0.9406 \\
(0.0139)\end{array}$ & $\begin{array}{c}0.8474 \\
(0.0748)\end{array}$ & $\begin{array}{c}0.8604 \\
(0.1938)\end{array}$ & $\begin{array}{c}0.8740 \\
(0.3400)\end{array}$ \\
\hline & & $C I_{\delta . G C I}$ & $\begin{array}{c}0.9490 \\
(0.0141)\end{array}$ & $\begin{array}{c}0.9490 \\
(0.0770)\end{array}$ & $\begin{array}{c}0.9450 \\
(0.1986)\end{array}$ & $\begin{array}{c}0.9514 \\
(0.3740)\end{array}$ \\
\hline & & $C I_{\delta . A G C I}$ & $\begin{array}{c}0.9492 \\
(0.0141)\end{array}$ & $\begin{array}{c}0.9486 \\
(0.0769)\end{array}$ & $\begin{array}{c}0.9444 \\
(0.1982)\end{array}$ & $\begin{array}{c}0.9498 \\
(0.3732)\end{array}$ \\
\hline & & $C I_{\delta . C A}$ & $\begin{array}{c}0.9514 \\
(0.0139)\end{array}$ & $\begin{array}{c}0.9472 \\
(0.0758)\end{array}$ & $\begin{array}{c}0.9446 \\
(0.1945)\end{array}$ & $\begin{array}{c}0.9492 \\
(0.3652)\end{array}$ \\
\hline & & $C I_{\delta . B S}$ & $\begin{array}{c}0.9478 \\
(0.0140)\end{array}$ & $\begin{array}{c}0.9476 \\
(0.0763)\end{array}$ & $\begin{array}{c}0.9460 \\
(0.1969)\end{array}$ & $\begin{array}{c}0.9538 \\
(0.3704)\end{array}$ \\
\hline & & $C I_{\delta . A B S 1}$ & $\begin{array}{c}0.9484 \\
(0.0140)\end{array}$ & $\begin{array}{c}0.9484 \\
(0.0763)\end{array}$ & $\begin{array}{c}0.9456 \\
(0.1970)\end{array}$ & $\begin{array}{c}0.9536 \\
(0.3700)\end{array}$ \\
\hline & & $C I_{\delta . A B S 2}$ & $\begin{array}{c}0.9482 \\
(0.0140)\end{array}$ & $\begin{array}{c}0.9484 \\
(0.0762)\end{array}$ & $\begin{array}{c}0.9468 \\
(0.1966)\end{array}$ & $\begin{array}{c}0.9540 \\
(0.3699)\end{array}$ \\
\hline
\end{tabular}




\section{EMPIRICAL APPLICATION}

The coefficient of variation is commonly used in the analysis of environmental data (Thangjai et al. 2019). Hence, data for the level of lead in air were used to construct the confidence intervals for the coefficient of variation for a single normal population, while data on carbon monoxide emissions in two areas were used to test the confidence intervals for the difference between the coefficients of variation of two populations.

Example 1 Data on air lead levels $\left(\mu \mathrm{g} \mathrm{m}^{-3}\right)$ of 15 sites at the Alma American Laboratories, Fairplay, Colorado, USA on 23 February 1989 were used to illustrated the performances of the proposed approaches (Krishnamoorthy et al. 2006). The data were 200, 120, $15,7,8,6,48,61,380,80,29,1000,350,1400$, and 110 and fit a log-normal distribution, i.e. the logarithms of the data a normal distribution. The basic statistics after the log-transformation of the data are $\bar{x}=4.3329$ and $s^{2}=3.0257$, and the biased estimator and the asymptomatically unbiased estimator of the coefficient of variation are $\hat{\theta}=0.4015$ and $\widetilde{\theta}=0.3945$, respectively. The confidence intervals for the coefficient of variation of the normal distribution are given in Table 4. The numerical results show that all of the confidence intervals contain the true coefficient of variation. However, the lengths of the computational approach and the two approximately unbiased estimators of Mahmoudvand and Hassani (2009) were shorter than those of the others. These results are in agreement with the simulation results in terms of average length when the sample size is small and the coefficient of variation is large.

TABLE 4. The 95\% two-sided confidence intervals for the coefficient of variation of single normal distribution

\begin{tabular}{cccc}
\hline Approach & Lower limit & Upper limit & Length of interval \\
\hline$C I_{\theta . M H 1}$ & 0.2899 & 0.6169 & 0.3270 \\
$C I_{\theta . M H 2}$ & 0.2325 & 0.5564 & 0.3239 \\
$C I_{\theta . M O V E R}$ & 0.1987 & 3.0480 & 2.8493 \\
$C I_{\theta . G C I}$ & 0.2870 & 0.7048 & 0.4178 \\
$C I_{\theta . A G C I}$ & 0.2778 & 0.6934 & 0.4156 \\
$C I_{\theta . C A}$ & 0.2355 & 0.5797 & 0.3442 \\
$C I_{\theta . B S}$ & 0.2685 & 0.6357 & 0.3673 \\
$C I_{\theta . A B S 1}$ & 0.2609 & 0.6352 & 0.3743 \\
$C I_{\theta . A B S 2}$ & 0.2557 & 0.6280 & 0.3723 \\
\hline
\end{tabular}

Example 2 This dataset was from the Data and Story Library (http://lib.stat.cmu.edu/DASL) (Zou et al. 2009). The data contains carbon monoxide emissions from an oil refinery near San Francisco in April - May 1993. The refinery submitted 31 daily measurements from its stack to the Bay Area Air Quality Management District. The Bay Area Air Quality Management District made nine measurements from September 1990 to March 1993. The data are

Refinery 45, 30, 38, 42, 63, 43, 102, 86, 99, 63, 58, 34, 37, $55,58,153,75,58,36,59,43,102,52,30,21$, $40,141,85,161,86,71$

District Management 12.5, 20, 4, 20, 25, 170, 15, 20, 15.
Both datasets fit a log-normal distribution. The sample statistics from the log-transformation of the data are as follows:

Refinery $n=31, \bar{x}=4.0743, s_{X}^{2}=0.2521, \hat{\theta}_{X}=0.1232$ District Management $m=9, \bar{y}=2.9633, s_{Y}^{2}=0.9496$, $\hat{\theta}_{Y}=0.3288$.

The difference between the coefficients of variation is $\hat{\delta}=-0.2056$. The confidence intervals for the difference between the coefficients of variation of two normal distributions are reported in Table 5. All of the confidence intervals contain the true difference between the coefficients of variation of the two distributions. The computational approach and two approaches of Niwitpong (2015) based on the approximately unbiased 
estimators of Mahmoudvand and Hassani (2009) yielded shorter lengths than the others. Therefore, these results are in agreement with the simulation results for small sample sizes.

From the results in Tables 4 and 5, it can be concluded that the computational approach (CA) and the two approximately unbiased estimators of Mahmoudvand and Hassani (2009) (MH1, MH2) are recommended for estimating the confidence intervals for the coefficient of variation of the single normal distribution and the difference between the coefficients of variation of the two normal distributions.

TABLE 5. The 95\% two-sided confidence intervals for the difference between the coefficients of variation of two normal distributions

\begin{tabular}{cccc}
\hline Approach & Lower limit & Upper limit & Length of interval \\
\hline$C I_{\delta . M H 1}$ & -0.3580 & -0.0532 & 0.3048 \\
$C I_{\delta . M H 2}$ & -0.3711 & -0.0402 & 0.3309 \\
$C I_{\delta . M O V E R}$ & -1.6729 & 0.6303 & 2.3032 \\
$C I_{\delta . G C I}$ & -0.5698 & -0.0802 & 0.4896 \\
$C I_{\delta . A G C I}$ & -0.5838 & -0.0759 & 0.5079 \\
$C I_{\delta . C A}$ & -0.3636 & -0.0378 & 0.3258 \\
$C I_{\delta . B S}$ & -0.4955 & -0.0581 & 0.4374 \\
$C I_{\delta . A B S 1}$ & -0.4861 & -0.0528 & 0.4333 \\
$C I_{\delta . A B S 2}$ & -0.4694 & -0.0517 & 0.4177 \\
\hline
\end{tabular}

\section{DISCUSSION AND CONCLUSION}

Mahmoudvand and Hassani (2009) proposed two approximately unbiased estimators and Donner and Zou (2012) used the method of variance estimates recovery (MOVER) approach to construct the confidence intervals for the coefficient of variation of a normal distribution. Furthermore, Niwitpong (2015) extended the two approximately unbiased estimators of Mahmoudvand and Hassani (2009) and the MOVER approach of Donner and Zou (2012) to estimate the confidence intervals for the difference between the coefficients of variation of normal distributions with bounded parameters. In this paper, generalized confidence interval (GCI), adjusted GCI, computational, Bayesian, and two adjusted Bayesian approaches are presented for the confidence interval estimation of the coefficient of variation of a normal distribution and the difference between the coefficients of variation of two normal distributions. These approaches were compared with the existing approaches via simulation studies. The results indicate that the Bayesian approach and two adjusted Bayesian approaches attained satisfactory coverage probabilities and average lengths for all cases in the first scenario and when the sample sizes were large in the second scenario.

As a final note, Niwitpong (2015) proposed approximate Bayesian confidence intervals for the coefficient of variation of a Gaussian distribution based on the square error and the Higgins-Tsokos loss function. In this study, the highest posterior density interval is used to construct the Bayesian confidence interval that is easier to compute than Niwitpong (2015) approaches. This is because the square error loss function uses a suitable approximation of the Pareto prior and uses the close relationship between confidence interval and hypothesis testing.

\section{ACKNOWLEDGEMENTS}

This research was funded by the King Mongkut's University of Technology North Bangkok. Grant No. KMUTNB-63-KNOW-032. 


\section{REFERENCES}

Bayes, T. 1763. An essay towards solving a problem in the doctrine of chances. Philosophical Transactions of the Royal Society of London 53: 370-418.

Bernat, D.H., Lazovich, D., Forster, J.L., Oakes, J.M. \& Chen, V. 2009. Area-level variation in adolescent smoking. Preventing Chronic Disease 6(2): 1-8.

Camara, V.A.R. 2012. New approximate Bayesian confidence intervals for the coefficient of variation of a Gaussian distribution. Journal of Modern Applied Statistical Methods 11(1): 158-166.

Camara, V.A.R. 2003. Approximate Bayesian confidence intervals for the variance of a Gaussian distribution. Journal of Modern Applied Statistical Methods 2(2): 350358.

Chow, P.K., Wan, C.P., Yip, S.P. Tsim, Y.L., Tsang, K.S., Li, K.F., Wong, H.F., Leung, K.K. \& Lee, W.C. 1998. Haematology \& Serology. Hong Kong Medical Technology Association Quality Assurance Programme Biennial Report 1997 \& 98: $15-27$

Donner, A. \& Zou, G.Y. 2012. Closed-form confidence intervals for functions of the normal mean and standard deviation. Statistical Methods in Medical Research 21(4): 347-359.

Doornbos, R. \& Dijkstra, J.B. 1983. A multi sample test for the equality of coefficients of variation in normal populations. Communications in Statistics-Simulation and Computation 12(2): 147-158.

Fung, W.K. \& Tsang, T.S. 1998. A simulation study comparing tests for the equality of coefficients of variation. Statistics in Medicine 17(17): 2003-2014.

Gelman, A., Carlin, J.B., Stern, H.S., Dunson, D.B., Vehtari, A. \& Rubin, D.B. 2013. Bayesian Data Analysis. Florida: Chapman and Hall/CRC. pp. 29-62.

Gül, H.H., Gökpinar, E., Ebegil, M., Özdemir, Y.A. \& Gökpinar, F. 2019. A new test for the homogeneity of inverse Gaussian scale parameters based on computational approach test. Sains Malaysiana 48(8): 1777-1785

Gulhar, M., Kibria, B.M.G., Albatineh, A.N. \& Ahmed, N.U. 2012. A comparison of some confidence intervals for estimating the population coefficient of variation: A simulation study. Statistics and Operations Research Transactions 36(1): 45-68.

Harvey, J. \& van der Merwe, A.J. 2012. Bayesian confidence intervals for means and variances of lognormal and bivariate lognormal distributions. Journal of Statistical Planning and Inference 142(6): 1294-1309.

Harvey, J., Groenewald, P.C.N. \& van der Merwe, A.J. 2010. Bayesian Confidence Intervals for the Mean of a Lognormal Distribution: A Comparison with the MOVER and Generalized Confidence Interval Procedure. Technical Report No. 408. Department of Statistics and Actuarial Science, University of the Free State. pp. 1-28

Kang, C.W., Lee, M.S., Seong, Y.J. \& Hawkins, D.M. 2007. A control chart for the coefficient of variation. Journal of Quality Technology 39(2): 151-158.

Krishnamoorthy, K., Mathew, T. \& Ramachandran, G. 2006. Generalized P-values and confidence intervals: A novel approach for analyzing lognormally distributed exposure data. Journal of Occupational and Environmental Hygiene 3(11): 642-650.

Lim, S.L., Yeong, W.C., Khoo, M.B.C. \& Chew, X.Y. 2018. A comparison of the variable sampling interval (VSI) and variable sample size (VSS) coefficient of variation charts. Proceedings of the 4th World Congress on Mechanical, Chemical, and Material Engineering 129: 1-8.

Liu, S., Qin, G., Wang, B. \& Zhou, H. 2015. Confidence interval estimation for coefficient of variation. Georgia State University, M.Sc. Thesis (Unpublished).

Mahmoudvand, R. \& Hassani, H. 2009. Two new confidence intervals for the coefficient of variation in a normal distribution. Journal of Applied Statistics 36(4): 429-442.

McKay, A.T. 1932. Distribution of the coefficient of variation and the extended ' $t$ ' distribution. Journal of Royal Statistics Society 95(4): 695-698.

Menzefricke, U. 2010. Control charts for the variance and coefficient of variation based on their predictive distribution. Communications in Statistics-Theory and Methods 39(16): 2930-2941.

Niwitpong, S. 2015. Confidence intervals for the difference between coefficients of variation of normal distribution with bounded parameters. Far East Journal of Mathematical Sciences 98(5): 649-663.

Rao, K.A. \& D'Cunha, J.G. 2016. Bayesian inference for median of the lognormal distribution. Journal of Modern Applied Statistical Methods 15(2): 526-535.

Saelee, V., Kornpetpanee, S. \& Wongkasem, P. 2013. An examination of the variability of agricultural production using a new approximate confidence interval for the coefficient of variation. ScienceAsia 39: 440-443.

Singh, M. 1993. Behavior of sample coefficient of variation drawn from several distributions. Sankya 55(1): 65-76.

Taye, G. \& Njuho, P. 2008. Monitoring field variability using confidence interval for coefficient of variation. Communications in Statistics-Theory and Methods 37(6): 831-846.

Thangjai, W., Niwitpong, S. \& Niwitpong, S. 2020. Adjusted generalized confidence intervals for the common coefficient of variation of several normal populations. Communications in Statistics-Simulation and Computation 49(1): 194-206.

Thangjai, W., Niwitpong, S. \& Niwitpong, S. 2019. Simultaneous confidence intervals for all differences of coefficients of variation of log-normal distributions. Hacettepe Journal of Mathematics and Statistics 48(5): 1505-1521.

Tian, L. 2005. Inferences on the common coefficient of variation. Statistics in Medicine 24(14): 2213-2220.

Tongmol, N., Srisodaphol, W. \& Boonyued, A. 2016. A Bayesian approach to the one-way ANOVA under unequal variance. Sains Malaysiana 45(10): 1565-1572.

van Zyl, R. \& van der Merwe, A.J. 2017. A Bayesian control chart for a common coefficient of variation. Communications in Statistics-Theory and Methods 46(12): 5795-5811.

Vangel, M.G. 1996. Confidence intervals for a normal coefficient of variation. Journal American Statistical Association 50(1): 21-26.

Verrill, S. \& Johnson, R.A. 2007. Confidence bounds and hypothesis tests for normal distribution coefficients of 
variation. Communications in Statistics-Theory and Methods 36(12): 2187-2206

Weerahandi, S. 1995. Exact Statistical Methods for Data Analysis. New York: Springer-Verlag. pp. 57-58.

Wong, A.C.M. \& Wu, J. 2002. Small sample asymptotic inference for the coefficient of variation: Normal and nonnormal models. Journal of Statistical Planning and Inference 104(1): 73-82.

Zhang, J., Li, Z. \& Wang, Z. 2018. Control chart for monitoring the coefficient of variation with an exponentially weighted moving average procedure. Quality and Reliability Engineering International 34(2): 188-202.

Zou, G.Y., Huo, C.Y. \& Taleban, J. 2009. Simple confidence intervals for lognormal means and their differences with environmental applications. Environmetrics 20(2): 172-180.
Warisa Thangjai

Department of Statistics, Faculty of Science

Ramkhamhaeng University

Bangkok 10240

Thailand

Sa-Aat Niwitpong* \& Suparat Niwitpong

Department of Applied Statistics

Faculty of Applied Science

King Mongkut's University of Technology North Bangkok

Bangkok 10800

Thailand

*Corresponding author; email: sa-aat.n@sci.kmutnb.ac.th

Received: 26 October 2019

Accepted: 30 June 2020 